\title{
La invasión de la metrópoli: la literatura latinoamericana en Madrid y Barcelona
}

Pablo Sánchez

F n un artículo de 1927, el novelista cubano Alejo Carpentier, Eentonces todavía poco conocido, planteaba con una metáfora afectiva el mayor peligro, a su juicio, de las relaciones culturales entre España y Latinoamérica: "creo deplorable que se intente transformar un afecto fraternal en incesto" (1998: 97). Carpentier trataba de separar claramente las dos orillas del Atlántico en el terreno cultural y evitar cualquier nueva subordinación a la metrópoli. En realidad, ni siquiera el incesto era la metáfora sexual más exacta para representar la inquietud que le motivó a redactar el texto al que hago referencia; los elementos de dominio y poder y la conquista de una ansiada madurez posedípica frente a la madre patria parecen más ajustados al caso. La reacción de Carpentier venía a denunciar rotundamente las pretensiones de algunos intelectuales de Madrid de proponer a la capital de España como centro de la cultura hispánica, desplazando a un segundo plano el tradicional encanto sensual y vanguardista de París. De la capital francesa, espacio de culto para los escritores latinoamericanos desde finales del siglo XIX, procedían las principales novedades estéticas, y el propio Carpentier coincidió con Miguel Ángel Asturias en los años tan impactantes del surrealismo francés. La superioridad mítica de París resumía el impulso eurocéntrico de 
los escritores latinoamericanos y la fuerza renovadora con la cual pretendían modernizar la cultura de sus respectivos países.

Las palabras de Carpentier corresponden a la llamada polémica del meridiano cultural de Hispanoamérica, iniciada por un artículo de la revista madrileńa La Gaceta Literaria que la crítica (Alemany, 20-29) ha atribuido a uno de los personajes de más importancia transatlántica en esos años, el poeta y crítico Guillermo de Torre, para más señas familiares, cuñado de Jorge Luis Borges y curioso ejemplo de miopía editora por su currículum de famosos rechazos como Residencia en la tierra, La hojarasca y El túnel. De Torre había participado en el ultraísmo español, primer movimiento de vanguardia peninsular, y se había mostrado muy activo en la divulgación de las primicias estéticas europeas.

Con el artículo de La Gaceta Literaria que Alemany le atribuye, De Torre pretendía simplemente promocionar Madrid como nuevo meridiano cultural (Alemany, 66-67), es decir, proponía una centralización alternativa de la cultura que, según él, fuera más favorable a los intereses de la comunidad hispánica y que desafiara el impulso centrípeto hacia París, pero con ello sólo consiguió irritar inmediatamente a los jóvenes vanguardistas argentinos del grupo martinfierrista entre los que se encontraba el joven Borges, ya bastante recuperado de su erupción ultraísta. Los argentinos vieron la propuesta del español De Torre como un retorno del colonialismo cultural y una exhibición de soberbia metropolitana, aunque probablemente había motivos personales detrás de la invectiva (relacionados con la paternidad del ultraísmo). A partir de ahí, otros muchos escritores e intelectuales de ambos lados del océano, como el mismo Carpentier, se sumaron a una polémica que, como tantas otras veces, tenía la gratuidad idónea para el ejercicio retórico y para la suma de confusiones.

Sin embargo, por detrás del artificio de reprimendas y golpes bajos, la cuestión en juego era ni más ni menos que la influencia de un sistema literario sobre otro, tema que no era en absoluto desdeña- 
ble en esos años porque afectaba a las identidades culturales creadas desde la emancipación de las colonias en el siglo XIX y a la autoafirmación de los escritores en el periodo vanguardista. La polémica del meridiano cultural de Hispanoamérica es, sin duda, uno de los episodios más significativos y ruidosos en la relación que la metrópoli y las antiguas colonias mantuvieron durante el pasado siglo. En esa ocasión Madrid, o más exactamente, instituciones y figuras del campo literario madrileño trataron de reorientar la dirección global de la literatura en lengua espańola. No lo consiguieron; curiosamente, la ciudad rival económica y políticamente, Barcelona, sí lo consiguió algunas décadas después.

De todos modos, en esa década de los veinte, la metrópoli había recuperado una parte de su hegemonía cultural e influía en el repertorio de otras literaturas en lengua española: Juan Ramón Jiménez influye en los poetas del grupo mexicano Contemporáneos, Ramón Gómez de la Serna se consagra como vanguardista antonomásico y difunde su magisterio por Argentina; la plataforma cultural de Ortega y Gasset, la Revista de Occidente, populariza los debates sobre el arte nuevo y terminará incluso ayudando a la creación, a su imagen y semejanza, de la revista Sur a partir de 1931; Alfonso Reyes y Pedro Henríquez Ureña, los creadores del canon latinoamericano, perfeccionan su técnica filológica al amparo de la escuela de Menéndez Pidal, y el mismo Guillermo de Torre se convierte en el otro gran teórico de la vanguardia, con pleitos bastante conocidos como el que sostuvo con Vicente Huidobro.

$\mathrm{Y}$ a toda esa actividad hay que sumar otra circunstancia decisiva que en ocasiones pasa inadvertida a pesar de su importancia socioliteraria: las editoriales españolas, ya desde los tiempos de Rubén Darío, empiezan a descubrir el potencial literario de Hispanoamérica. No quiero abrumar con una acumulación de datos, pero vale la pena recordar que el propio Alejo Carpentier publicará, un poco más tarde de la declaración que cité, en España su primera novela, Ecué-Yamba- 
Ó, y lo mismo hará Miguel Ángel Asturias con sus Leyendas de Guatemala, que posteriormente serán traducidas al francés con prólogo de Paul Valéry. Asimismo, el reconocimiento fuera de Perú de César Vallejo se iniciará con la publicación de Trilce en la editorial de José Bergamín, Cruz y Raya, con prólogo de Gerardo Diego, la misma editorial donde Pablo Neruda publicara finalmente su Residencia en la tierra. El mismo Vallejo publica su novela El tungsteno en la editorial madrileńa Cenit. Y, en lo que respecta a Barcelona, donde ya el propio Rubén Darío había publicado su autobiografía, la editorial Araluce en 1929 publica uno de los grandes éxitos comerciales y estéticos de la novela regionalista: Doña Bárbara, del venezolano Rómulo Gallegos, que publicará el resto de su obra en la misma editorial barcelonesa. Siguiendo la metáfora de Alejo Carpentier, podríamos decir maliciosamente que más de uno buscaba el incesto por dinero o, en términos de Bourdieu, por capital simbólico. En ese sentido, parece que la preocupación de Carpentier escondía el peligro bastante real de que la solidez editorial española reorientara la práctica de los escritores latinoamericanos y creara una nueva forma de dependencia.

Ciertamente, el poderío editorial de Madrid y Barcelona es un fenómeno fundamental para entender los diferentes casos de interferencia y convivencia entre las literaturas en lengua espańola durante el siglo XX (muy diferente sería el caso de la literatura brasileña, casi totalmente desconocida en España y fuera de las estrategias editoriales madrileńas y barcelonesas). De hecho, puede parecer incluso que es el vínculo más potente que ha relacionado históricamente ambos sistemas y sin duda lo podemos comprobar hoy: los autores latinoamericanos más famosos, como Mario Vargas Llosa o Carlos Fuentes, publican en editoriales españolas, que además tienen los premios literarios más tentadores económicamente (Alfaguara, Primavera, Planeta, Biblioteca Breve), aunque no siempre ofrezcan los mejores resultados literarios, $\mathrm{y}$ han acaparado el mercado editorial en lengua espańola aprovechando la crisis de la edición latinoamericana. Por 
encima de engañosos lemas panhispanistas y de esfuerzos armonizadores, es la realidad del mercado la que impone ahora mismo la atracción de los escritores latinoamericanos por las editoriales madrileñas y barcelonesas. No es el tema que más me interesa aquí y esperemos que pronto sea estudiado con el rigor y la objetividad necesarios, pero no cabe duda de que en los últimos años se ha producido, paralelamente a la invasión de bancos y empresas espańoles, una poderosa entrada de editoriales que han reconfigurado el mercado literario latinoamericano de acuerdo a sus obvios intereses comerciales y con consecuencias quizá alienantes. En ese sentido, tal vez estamos viviendo un momento de sutil recolonización ante el cual, curiosamente, no abundan las respuestas airadas como la de Carpentier o la de los martinfierristas. Se trataría, pues, de una nueva etapa cuyo diagnóstico todavía está pendiente, aunque quizá podamos entenderlo mejor a la luz de la relación tradicional entre España y Latinoamérica y de la dificultad de la literatura latinoamericana para encontrar un campo autónomo de producción artística.

El vigor editorial de la metrópoli no es el único factor de conexión cultural, naturalmente; podemos recordar también la importancia del exilio político latinoamericano, sobre todo en la década de los setenta, que llevó entre otros a Onetti y Benedetti a tierras espańolas, e incluso podríamos recordar aquí otra importantísima conexión de los intelectuales de lengua española, que fue la que se produjo con motivo de la Guerra Civil Española, y que tendría su manifestación más célebre en el Congreso de Intelectuales Antifascistas organizado precisamente en Madrid, Barcelona y Valencia en 1937. La Guerra Civil Española sería además el referente de dos poemas militantes como España en el corazón, de Pablo Neruda y, sobre todo, España, aparta de mi este cáliz, de César Vallejo.

Sea por el exilio o por la hegemonía editorial, las dos grandes ciudades españolas y sus instituciones literarias han tenido una relación particular con la literatura latinoamericana, que es la que aquí vamos 
a intentar reconstruir. $\mathrm{Y}$ es que, desde luego, la historia es bastante compleja: no siempre la metrópoli ha sabido reconocer adecuadamente los méritos culturales de sus ex colonias, y del mismo modo, en ocasiones, la pretensión de autonomía de la cultura latinoamericana ha dificultado innecesariamente el flujo de intercambios y la comunicación transoceánica. Los vaivenes de esa relación, sus matices, desafíos y controversias, constituyen en conjunto un capítulo poco estudiado, sea por un excluyente bolivarismo, por un vanidoso casticismo o por los múltiples efectos distorsionadores del nacionalismo, tanto del lado de acá como del lado de allá.

Nos interesa, por tanto, trazar una breve historia de la recepción de la literatura latinoamericana en Madrid y en Barcelona y discutir la importancia de las dos ciudades como centros culturales y socioliterarios en el ámbito de lengua española. Como podremos comprobar, por encima de la rivalidad de dos importantes centros económicos y políticos, hay diferencias sustanciales que vienen en buena medida determinadas por la condición híbrida y bilingüe de la cultura catalana y que han terminado creando dos modelos distintos de relación con las antiguas colonias americanas. Al fin y al cabo, Madrid fue la capital de la España franquista y Barcelona la capital del nacionalismo catalán, que florece durante las primeras décadas del siglo XX, tanto cultural como económicamente, para ser después reprimido durante los casi cuarenta años de la dictadura de Franco.

Podemos ver algunas consecuencias culturales de ese conflicto a propósito de los escritores latinoamericanos. Estableciendo una cronología un tanto apresurada, diríamos que una primera etapa abarcaría desde la llegada de Rubén Darío como corresponsal de La Nación en 1899 hasta el estallido de la Guerra Civil en 1936. Rubén destaca en sus crónicas una idea general que encontraremos con las lógicas variaciones, en otro ilustre latinoamericano que residió provisionalmente en España, Mario Vargas Llosa. Se trata de la diferencia de receptividad entre Madrid y Barcelona: Rubén elogia el entusiasmo 
del modernismo catalán tras su visita a Barcelona y critica la apatía y el anquilosamiento madrileños, que él precisamente dinamizara a través de su presencia y de sus contactos con la juventud modernista española. En los textos de España contemporánea, Rubén se queja de la escasa información que la Espańa de la Restauración tiene de las novedades literarias latinoamericanas y especialmente de la joven literatura modernista: "no existe en Madrid, ni en el resto de España, con excepción de Cataluña, ninguna agrupación, brotherhood, en que el arte puro -o impuro, señores preceptistas- se cultive siguiendo el movimiento que en estos últimos tiempos ha sido tratado con tanta dureza por unos, con tanto entusiasmo por otros [y falta] la influencia de todo soplo cosmopolita, como asimismo la expansión individual, la libertad, digámoslo con la palabra consagrada, el anarquismo en el arte, base de lo que constituye la evolución moderna o Modernista" (254).

Si bien el juicio de Rubén es drástico en ocasiones, anticipa un rasgo básico de lo que luego será la antinomia Madrid-Barcelona, sobre todo, como veremos, en los ańos sesenta y setenta. Barcelona adquiere una identidad como ciudad más porosa y cosmopolita, en parte por razones comerciales y geográficas, y Madrid, en lo que respecta a su ambiente cultural, se presenta como una ciudad más endogámica y hermética; Vargas Llosa, por ejemplo, se referirá a la capital castellana en los sesenta como un "mundillo pequeñito, cerrado, provinciano y culturalmente ensimismado" (1992: 13). Al margen de la superficialidad que implica una categorización tan estricta, es cierto que una cierta oposición entre las dos grandes capitales espańolas se ha dado más allá del mundialmente conocido terreno futbolístico y dentro del más específico de la producción cultural. Esa oposición cobrará más importancia cuando en los años del famoso boom de la narrativa latinoamericana Barcelona acapare las principales conexiones socioliterarias con Latinoamérica y descubra, antes que Madrid, el gran negocio de la nueva novela de García Márquez, Vargas Llosa y demás. 
Sin embargo, poco antes de la Guerra Civil, Madrid había conseguido una mayor proximidad a la cultura latinoamericana, en parte por la importante presencia de Neruda y Vallejo. La Guerra Civil, naturalmente, significó una fractura del sistema literario español y, entre otros cambios, supuso una disminución evidente del vigor editorial espańol y de la comunicación con el exterior, incluso con la América hispánica. La quiebra española coincidió en la década de los cuarenta con una primera fase del crecimiento editorial latinoamericano, gracias también a la aportación de editores españoles instalados en Hispanoamérica, como es el caso de Emecé o Losada, y por supuesto a la aparición de lo que muy improvisadamente se ha llamado la nueva narrativa latinoamericana. Sin embargo, la obra de Borges, Asturias, Carpentier o Rulfo prácticamente no tiene eco en la España de la autarquía y la censura ultracatólica. De hecho, esa incomunicación es una de las claves para entender el papel que juegan Madrid y Barcelona en las décadas posteriores. Sólo desde esa ignorancia casi absoluta, con la excepción de algún crítico avezado como Jorge Campos, puede entenderse la compleja recepción de la literatura latinoamericana en España a partir de 1962 y la intervención de las editoriales españolas en la expansión comercial internacional de esa literatura. Una de las características de este proceso es precisamente el tardío y arbitrario reconocimiento por parte de la metrópoli de la riqueza y la complejidad de la producción literaria latinoamericana, usualmente limitada al marchamo simplificador y didáctico de un realismo mágico que en realidad nunca fue bien entendido en España. Como recuerda el crítico Ángel Rama, en España se conoció antes a Mario Vargas Llosa que a Julio Cortázar y a éste antes que a Jorge Luis Borges, lo que produjo un aplanamiento sincrónico que la crítica tuvo que enmendar dificultosamente (52). Hay casos más ridículos, como el hecho de que se conociera y divulgara antes a Jorge Onetti (finalista de un Premio Biblioteca Breve) que a su padre Juan Carlos. Lo que sucedió es bastante fácil de explicar hoy en día, 
aunque en su momento más de uno no parecía entenderlo bien: de manera bastante repentina, los lectores españoles entraron en contacto con una tradición cultural que mayoritariamente desconocían y algunos sintieron realmente el impacto como una invasión, como una usurpación. O simplemente la menospreciaron, aunque no fuera con mala voluntad. No de otro modo se puede entender la respuesta de uno de los novelistas españoles más importantes de la época, Juan Benet, en 1970 a la pregunta de qué es el boom. Benet lo resumía afirmando lo siguiente: "yo lo que sé es que existen tres buenos libros sudamericanos que hace treinta años no existían" (Tola de Habich, 36). Teniendo en cuenta que treinta años antes, Borges ya había publicado alguno de sus cuentos más célebres, parece claro que la biblioteca de Benet era muy limitada en cuestiones americanistas. Ya no se trata únicamente de la conocida antipatía de Benet por la obra de Cortázar, sino de una desinformación general sobre una literatura que, a ojos de los españoles, parecía nacer con Cien años de soledad, como si no existiera una tradición previa (salvo la obra de Euclides da Cunha, que sí parecía interesar al novelista español).

Todo se remonta a ese ańo de 1962, en el que se inicia una nueva etapa en la que Barcelona tendrá un protagonismo especial hasta el punto de convertirse en capital de la literatura latinoamericana, muy por encima de Madrid y compitiendo incluso con París, ritual escenario de la madurez del escritor latinoamericano desde finales del XIX. 1962 es el año en el que el joven y entonces desconocido novelista peruano Mario Vargas Llosa gana el Premio Biblioteca Breve con la novela La ciudad y los perros. La historia es bastante conocida pero nos conviene insistir en ella. ${ }^{1}$ El éxito de crítica y de público en España y pronto en Latinoamérica motivan a la editorial Seix Ba-

\footnotetext{
${ }^{1}$ La recepción de la narrativa hispanoamericana en España entre 1961 y 1982 ha sido estudiada ampliamente en Marco y a ese estudio remito para la ampliación del tema.
} 
rral y muy especialmente al editor catalán Carlos Barral a reorientar su política de publicaciones hacia la literatura latinoamericana, que era prácticamente desconocida en España y en Europa y que ofrecía dos ventajas importantes: un repertorio amplio de técnicas narrativas modernizadoras que rompían el horizonte de expectativas de los lectores espańoles y un sentido crítico que encajaba con el resistencialismo de los círculos intelectuales antifranquistas, especialmente los ubicados en Barcelona en torno a la editorial Seix Barral, que había promocionado con poco éxito la literatura española del realismo social en los años anteriores. En torno a esa editorial estaban algunos de los novelistas más importantes del momento, como Juan Goytisolo, Juan García Hortelano o Juan Marsé, así como poetas como Jaime Gil de Biedma, y críticos como Josep Maria Castellet. Era un grupo cohesionado gracias al liderazgo de Barral y a la actitud crítica hacia la dictadura franquista.

La función institucional y reguladora del círculo de Seix Barral contribuyó decisivamente a distinguir el espacio socioliterario barcelonés del madrileño, donde no siempre eran bien vistos escritores que, en algunos casos, eran catalanohablantes, como era el caso de Gabriel Ferrater, el poeta que dejó para la posteridad la curiosa y ambigua leyenda de haberse suicidado después de anunciar muchas veces que era una inmoralidad llegar a los cincuenta ańos de vida. Barcelona ya había liderado antes una reacción crítica hacia la cultura oficial franquista, pero la operación editorial iniciada con Mario Vargas Llosa convirtió a la capital catalana en un lugar atractivo para todos los escritores latinoamericanos y propició un lugar de encuentro para la vanguardia de la literatura en lengua espańola. El prestigio del Premio Biblioteca Breve, que también fue concedido a Guillermo Cabrera Infante y a Carlos Fuentes, entre otros, aumentó el interés por acercarse a la capital mediterránea. Y el tercer factor determinante fue la aparición en escena, a finales de la década de los sesenta, de un personaje de vital importancia y singularmente impenetrable 
hasta ahora a las investigaciones de la crítica: la agente literaria Carmen Balcells, responsable entre otras cosas de la profesionalización, a principios de los setenta, de Mario Vargas Llosa, a quien convenció para que se dedicara en Barcelona de tiempo completo a la literatura gracias a su generoso patrocinio. La eficacia gestora de Carmen Balcells supuso un avance inequívoco en la aspiración clásica del escritor latinoamericano: la profesionalización deseada al menos desde el modernismo. En ese sentido, no puede definirse el campo literario de lengua espańola y las posiciones de los escritores a partir de 1970 sin recordar la discreta pero implacable intervención de Balcells y su subterránea labor en beneficio de sus representados, que han llegado, como es el caso de García Márquez y Onetti a dedicarle algunas de sus novelas.

Todos estos factores contribuyeron a que Barcelona se configurara de manera un tanto inesperada como capital de la literatura latinoamericana. En la primera mitad de la década, el proceso es aún muy lento y son pocas las obras latinoamericanas editadas, al margen de las dos primeras novelas de Vargas Llosa, galardonadas además con el Premio de la Crítica. Pero a partir del éxito internacional indiscutible de Cien años de soledad en 1967, que curiosamente no fue publicada por Seix Barral, sino por la argentina Sudamericana, la literatura latinoamericana aumenta notoriamente su presencia en las librerías españolas y también en los medios de comunicación. Barcelona tenía otra gran ventaja que Carlos Barral supo aprovechar: no sólo era una excelente vía de entrada a la Europa occidental, sino que tenía una más efectiva capacidad de distribución para todo el continente latinoamericano, frecuentemente mal comunicado. Es decir: la literatura distribuida desde Barcelona llegaba curiosamente en mejores condiciones a diferentes latitudes latinoamericanas que la divulgada por las propias editoriales autóctonas.

Pero la crónica del periodo debe recuperar la importancia crucial de otros dos centros culturales sin los cuales no entenderíamos la red de relaciones y polémicas de esos años, que involucran de una ma- 
nera u otra a casi todos los escritores relevantes. El redescubrimiento de la literatura latinoamericana por parte de la editorial Seix Barral, bien conectada con editoriales europeas como Gallimard, coincide con otro acontecimiento fundamental: el triunfo de la Revolución Cubana, que genera un entusiasmo político entre la izquierda latinoamericana y española, al menos durante la década de los sesenta. La Habana se convierte en el centro cultural más importante del continente latinoamericano gracias a la proyección de Casa de las Américas, al carisma y la astucia de Fidel Castro como anfitrión y a los nuevos ideales políticos. Desde Barcelona, Carlos Barral, Juan Marsé, Josep Maria Castellet y José Agustín Goytisolo visitan en diferentes momentos la isla y son testigos, como otros muchos intelectuales latinoamericanos y europeos, del proceso de construcción socialista. De ese modo, nace una cohesión ideológica antidictatorial e izquierdista que fue decisiva en esos años y que favoreció la creación de una vanguardia transoceánica que aunaba la modernidad literaria con la utopía política. El círculo de Seix Barral se enlazaba así con la intelectualidad latinoamericana, lo que fortalecía la nueva alianza entre Barcelona y América (Sánchez López, 205-226).

Por otro lado, en París, donde residían por diversos motivos Julio Cortázar, Severo Sarduy y Juan Goytisolo, entre otros, nace a mediados de los sesenta la polémica revista Mundo Nuevo, dirigida por el crítico uruguayo Emir Rodríguez Monegal y sospechosamente financiada por fuentes próximas a la CIA. Mundo Nuevo promocionaba la nueva narrativa latinoamericana pero rechazaba la politización de la literatura impulsada por Casa de las Américas y, mucho menos dogmáticamente, por Seix Barral. Con ello la revista renovaba la centralidad de París, instauraba un contrapeso a la iniciativa de La Habana y configuraba un nuevo y complejo mapa de la literatura latinoamericana. ${ }^{2}$

\footnotetext{
2 Sobre los años sesenta latinoamericanos y sus principales polémicas políticas, es muy útil el balance de Gilman, aunque apenas incluye referencias españolas.
} 
Las tres ciudades, París, La Habana y Barcelona, se convirtieron así en el triángulo de lo que se llamó, con torpeza gacetillera, el boom de la narrativa latinoamericana, uno de los fenómenos decisivos de la cultura latinoamericana del siglo XX, tanto por su dimensión polémica como por su alcance estético, sociológico y aún económico. Ciertamente, las tres ciudades tenían ofertas diferentes e incluso con poca compatibilidad entre sí, pero contribuyeron a dinamizar el sistema literario en una etapa fértil, creativa e intensa como pocas. Desde La Habana y desde el núcleo de la política cultural revolucionaria cubana, la hostilidad hacia lo que llamaban los "intelectuales latinoparisinos colonizados" fue severa y aumentó con los años, con la excepción notoria de Julio Cortázar; por contra, el abstencionismo político del núcleo parisino les llevaba a defender la autonomía del escritor frente a las exigencias revolucionarias, lo que polarizó progresivamente la cultura latinoamericana en una repetición del esquema de la Guerra Fría. En Barcelona se vivía una situación intermedia, podríamos decir. La llegada de escritores latinoamericanos a la ciudad creó una pequeña colonia más o menos cómplice de los intelectuales catalanes antifranquistas y lo que se llamó la gauche divine: una elite izquierdista más o menos joven en la que se mezclaban editores, escritores y otros artistas. Por otro lado, el magnetismo editorial de la ciudad significaba también de algún modo una afrenta y un desafío a la ortodoxia doctrinaria de la Revolución Cubana. A finales de la década de los sesenta, nacieron dos nuevas editoriales, Tusquets y Anagrama, mientras que otras como Destino y Planeta empezaban a mostrar más interés por la "otra” literatura en español.

Madrid, en cambio, quedó en un evidente segundo plano en el desarrollo de este proceso socioliterario. Sus editoriales se incorporaron más tarde y con menor audacia; sus medios de comunicación tardaron en asumir la importancia del impulso modernizador que la narrativa latinoamericana supuso para la literatura española, e incluso podemos encontrar, como veremos, alguna forma de resistencia 
a lo que llegó a parecer hiperbólicamente una invasión de la cultura espańola por la novedad latinoamericana. Desde Madrid, ya en las décadas anteriores, el régimen franquista había tratado de restablecer los vínculos con Hispanoamérica a través de la creación de un organismo como el Instituto de Cultura Hispánica, pero su concepto de hispanidad y su oficialismo profranquista carecían de interés real para buena parte de los jóvenes escritores latinoamericanos, aún devotos del compromiso sartreano y visitantes asiduos de la nueva sociedad cubana.

De ese modo, la inmigración latinoamericana prefirió Barcelona a Madrid, a pesar del bilingüismo, y creó una colonia en la que destacaban los nombres de Mario Vargas Llosa, Gabriel García Márquez, José Donoso, Jorge Edwards, Sergio Pitol, Julio Ortega, Néstor Sánchez, Claribel Alegría y Humberto Moreno Durán, entre otros. La integración de Vargas Llosa y García Márquez, lógicamente los más destacados, con Carlos Barral y su círculo se confirmaba con la presencia de aquellos en algunos jurados de los premios literarios, el Biblioteca Breve y, después de la escisión de la casa Seix Barral, el Premio Barral Editores. El anecdotario de esos años es fundamental para entender la hegemonía de una vanguardia que, por primera vez desde los tiempos de la República, suma el talento de escritores latinoamericanos y espańoles en un proyecto común, improvisado y difuso, pero que resulta excepcional en el siglo XX.

En Barcelona se publica la tesis doctoral de Vargas Llosa sobre García Márquez, nunca reeditada, como sabemos, así como textos de la importancia de El obsceno pájaro de la noche o Conversación en la Catedral y, más adelante, El otoño del patriarca. Asimismo, en Barcelona, según cuenta José Donoso en su Historia personal del boom se celebró a finales de 1970 la reunión definitiva que daría lugar a la creación de la única revista concebida como órgano de esa nueva vanguardia: la revista Libre, que por motivos políticos no pudo publicarse en Espańa y que se organizó desde el exilio parisino de 
Juan Goytisolo. ${ }^{3}$ Los intereses editoriales no parecían, entonces, incompatibles con la vocación de ruptura política, aunque ya habían aparecido las primeras muestras, aún bastante privadas, de decepción por el giro represivo del régimen cubano.

De todos estos escritores, Vargas Llosa es el que más frecuentemente ha repasado su experiencia barcelonesa, que siempre tiene connotaciones positivas. "Quizás lo más importante, y eso lo viví yo muy de cerca durante los cinco ańos en que estuve en Barcelona, fue el que los jóvenes escritores hispanoamericanos, argentinos, colombianos, peruanos, nicaragüenses, llegaran en esos ańos traídos por el prestigio, por toda la mitología que había generado Barcelona. Venían aquí un poco como íbamos los de mi generación y los de generaciones anteriores a París" (1998: 170). Vargas Llosa también ha comparado la Barcelona que conoció con la Barcelona posterior a las Olimpiadas dominada por el ascenso político de los sectores nacionalistas: "Barcelona era entonces, todavía, pobretona, cosmopolita y universal; ahora es riquísima, nacionalista y provinciana. Como antes se desbordaba, culturalmente, hacia el resto del mundo, ahora parece fascinada por su propio ombligo" (1992: 13). El novelista peruano recuerda con nostalgia a los amigos catalanes que ya no están, como Jaime Gil de Biedma, Carlos Barral y Gabriel Ferrater y ha relatado algunas de las anécdotas de aquella elite excéntrica que podía pasar 24 horas seguidas bebiendo, como Ferrater, y mantener una incuestionable lucidez. De Barral, por ejemplo, afirmó Vargas Llosa: "él publicó mi primera novela, luchando como un tigre para que salvara el obstáculo de la censura, me hizo dar premios, traducir a varias lenguas, me inventó como escritor. Ya se ha dicho todo lo que hace falta sobre el ventarrón refrescante que fue, para la embotellada cultura de España de hace treinta ańos, la labor de Carlos en Seix Barral. Pero nunca se dirá lo suficiente sobre el encanto del personaje que creó de

${ }^{3}$ Cfr. Gilman (280-306). 
sí mismo y sobre el hechizo que era capaz de ejercer, entonces, antes de las durísimas pruebas que tuvo que sobrellevar" (1992: 13).

Vargas Llosa vivió en Barcelona, en el barrio de Sarriá, entre 1970 y 1974, año en que decidió regresar a Lima. Pero en 1974 ya muchas cosas habían cambiado y habían afectado, entre otros, al propio Carlos Barral y a esa cohesión entre intelectuales de lengua española (y algunos de lengua catalana, no lo olvidemos). El memorial de agravios había empezado en 1969 con las primeras muestras de resistencia a la hegemonía editorial de los latinoamericanos y Barcelona. El antagonismo cultural entre Madrid y Barcelona había dejado desplazados a muchos novelistas españoles, usuarios habituales del realismo crítico, que perdieron el favor de los lectores y de una crítica entusiasmada con la novedad estética de los latinoamericanos y sus artificios literarios modernizadores, como la técnica del diálogo telescópico de Vargas Llosa. La reacción llegó a propósito de una conferencia en la que el novelista Alfonso Grosso arremetió, provocadoramente, contra la sobrevaloración de los latinoamericanos, y de la polémica se hizo eco el suplemento literario del periódico madrileńo Informaciones. Madrid, por tanto, se convirtió en el primer foco de resistencia ante la hegemonía de los latinoamericanos y centró las tomas de posición de autodefensa de unos escritores que, aun siendo críticos con el franquismo, se habían beneficiado curiosamente del aislamiento cultural español. La polémica no tuvo mucho nivel teórico y es especialmente reveladora desde la perspectiva socioliteraria; en ella participaron nombres bastante olvidados del grupo realista, como Isaac Montero y Antonio Martínez Menchén, junto a alguno que otro crítico poco documentado y sin embargo muy patriota. ${ }^{4}$ Los argumentos conducían temerariamente hacia una oposición completamente banal entre

\footnotetext{
${ }^{4}$ Para una revisión de las diferentes polémicas, y especialmente la que tuvo lugar en el periódico Informaciones, cfr. Gras Miravet y Pablo Sánchez López (134-145) y Santana (130-138).
} 
novela espańola y latinoamericana, a pesar de que nadie quería reconocerlo abiertamente. Pero del embrollo crítico casi ningún analista pudo salir: se mezclaban la hostilidad más o menos encubierta hacia el círculo de Seix Barral con una ignorancia elemental de geografía y cultura americanas. El factor decisivo parecía escapar a todas las reflexiones: la invasión latinoamericana era contundente en número y calidad precisamente por la ausencia casi total en los treinta años anteriores. Toda la nueva narrativa latinoamericana era, efectivamente, una novedad incesante para los lectores españoles del momento. Si a ello añadimos la rentabilidad simbólica pero también económica adquirida por los latinoamericanos, la polémica se vuelve transparente. Pero su simplicidad no evitó que se reprodujera periódicamente, con variaciones en los nombres más que en los argumentos, al menos durante los cinco años siguientes. La reacción autóctona de autores conservadores como José María Gironella sorprendió especialmente a los propios latinoamericanos que incluso llegaron a publicar un libro de entrevistas titulado Los españoles y el boom.

La resistencia madrileña o castellana no fue la única toma de posición frente a la prosperidad del proyecto barcelonés. Desde Latinoamérica empezó a difundirse el concepto mafioso del boom que veía la vanguardia literaria como un invento de Carlos Barral y Carmen Balcells que estaba desestabilizando espuriamente la realidad cultural latinoamericana y sus tentativas de transformación política. Algunos críticos solventes como Ángel Rama promocionaron esa idea espectacular y agresiva, lo que dio lugar a discusiones como las que se llevaron a cabo en el Coloquio del Libro de Caracas en 1972, coincidiendo con la entrega del Premio "Rómulo Gallegos" a Gabriel García Márquez. La vanguardia en lengua española recibía la invectiva de los que temían la atrofia de la cultura latinoamericana. Y por último tuvo lugar la quiebra de la unidad política, a raíz de la detención en 1971 del poeta cubano Heberto Padilla, acusado de actividades contrarrevolucionarias por el régimen de Castro. Barcelona volvió 
a asumir un protagonismo especial en esta ocasión: allí se redactó la famosa carta de los 62, la carta en la que intelectuales europeos y latinoamericanos rechazaban la represión castrista y mostraban su indignación por la palinodia de Heberto Padilla, que se retractó públicamente de su desafección al régimen revolucionario cubano de un modo bastante grotesco. García Márquez y Cortázar no firmaron la carta, pero los Goytisolo, Vargas Llosa, Castellet y otros muchos intelectuales sí lo hicieron. ${ }^{5}$

La carta barcelonesa supuso la desarticulación del proyecto de vanguardia, formado de manera bastante casual, y por ese motivo terminó fracasando la experiencia de la revista Libre, que solamente aguantó cuatro números. Pero debemos evitar la mitificación de la carta como si fuera resultado de una conmoción espontánea e impredecible. La carta de los 62 exteriorizó divergencias ideológicas que se habían mantenido silenciadas en los años anteriores y que habían quedado en segundo plano ante la novedad de una complicidad, que, ahora lo sabemos, fue más aparente que real. Y no únicamente se debe a la cuestión cubana, sino a las diferencias en la conciencia de subdesarrollo y a la idea, cada vez más extendida entre los intelectuales, de que la España previa a la transición democrática no compartía ni el destino ni las urgencias de los países latinoamericanos. Los intereses diversos salieron finalmente a la luz y el proyecto utópico de la unidad transoceánica se desvaneció. Si a ello añadimos la pérdida de liderazgo de Carlos Barral y los nuevos rumbos de García Márquez y Vargas Llosa, los dos reclamos más importantes de la colonia latinoamericana, tendremos una perspectiva más clara de la atenuación progresiva de esa capitalidad de la que Barcelona gozó durante poco más de un lustro.

Pero no cabe duda de la importancia que el mundo editorial barcelonés tuvo para la literatura latinoamericana y de la excepcio-

${ }^{5}$ La principal documentación sobre la polémica se puede encontrar en "El caso Padilla”. 
nalidad de esa situación para la propia cultura de la ciudad catalana. Lo que, de todos modos, tampoco nos debe ocultar una última conclusión muy interesante. Porque el poderío editorial catalán y español no significó realmente que las ciudades españolas alcanzaran el estatuto simbólico de París en los propios textos literarios. El hecho de que los escritores publicaran asiduamente en España no supuso que los temas de la cultura y la sociedad espańola, por ejemplo, la ciudad como espacio, se incorporaran significativamente a la literatura latinoamericana. Vargas Llosa siguió escribiendo sobre Perú; el hecho de que el patriarca de García Márquez pueda estar construido, entre otros dictadores, a partir de la figura de Franco no es de todos modos un logro comparable, por ejemplo, al París de Cortázar. Barcelona fue, así, espacio comercial y extraliterario pero no narrativo. En realidad, es difícil encontrar novelas de la década cuyo espacio sea España. Por eso es especialmente destacable la obra de José Donoso El jardín de al lado (1981). En ella, Donoso narra la historia de un escritor chileno exiliado tras el golpe pinochetista, Julio Méndez, que se instala en Sitges, en la costa catalana, para buscar fortuna y tomar posición cerca de lo que el propio Donoso llamó el cogollo del boom. Quizá la novela no es la más importante de la producción de Donoso, pero sí es una valiosa reconstrucción de las nuevas circunstancias del mercado literario creadas en Barcelona a partir de los años sesenta. Incluso aparece la misteriosa Carmen Balcells transformada de forma bastante obvia en Núria Monclús, la todopoderosa agente literaria a la que denodadamente intenta impresionar Julio Méndez. Pero curiosamente, aunque Barcelona es el centro del poder literario en esa obra, el texto sitúa la acción primordial en Madrid, en los años de la transición democrática. Por ello podemos decir que, al menos en ese sentido, Madrid superó a Barcelona, ya que, aunque no consiguió los mayores beneficios del boom, sí aportó sus calles y barrios, el Museo del Prado y el Mercado del Rastro, a la literatura latinoamericana. 


\section{Bibliografía}

Alemany Bay, Carmen (comp.), 1998, La polémica del meridiano intelectual de Hispanoamérica (1927). Estudio y textos, Universidad de Alicante, Alicante.

Carpentier, Alejo, 1971, "El caso Padilla” en Libre 1, pp. 95-145.

, 1998, "Sobre el meridiano intelectual de Nuestra América" en Alemany Bay, Carmen (comp.), La polémica del meridiano intelectual de Hispanoamérica (1927). Estudio y textos, Universidad de Alicante, Alicante, pp. 95-97.

Darío, Rubén, 1987, España contemporánea, Lumen, Barcelona.

Torre, Guillermo de, 1998, "Madrid, meridiano intelectual de Hispanoamérica" en Alemany Bay, Carmen (comp.), La polémica del meridiano intelectual de Hispanoamérica (1927). Estudio y textos, Universidad de Alicante, Alicante, pp. 65-67.

Donoso, José, 1981, El jardín de al lado, Seix Barral, Barcelona.

, 1983, Historia personal del "boom”, Seix Barral, Barcelona.

Gilman, Claudia, 2003, Entre la pluma y el fusil. Debates y dilemas del escritor revolucionario en América Latina, Siglo XXI, México.

Gras Miravet, Dunia y Pablo Sánchez López, 2004, "La consagración de la vanguardia: 1967-1973” en Marco, Joaquín (ed.) y Jordi Gracia (coord.), La llegada de los bárbaros. La recepción de la literatura hispanoamericana en España (1960-1981), Edhasa, Barcelona, pp. 107-152.

Marco, Joaquín (ed.) y Jordi Gracia (coord.), 2004, La llegada de los bárbaros. La recepción de la literatura hispanoamericana en España (1960-1981), Edhasa, Barcelona.

Rama, Ángel, 1981, "El boom en perspectiva” en Viñas, David et al., Más allá del boom: literatura y mercado, Marcha, México, pp. 51-110.

Sánchez López, Pablo, 2007, "Utopía y desengaño de una generación: los escritores españoles y la Revolución Cubana" en Anales de la Literatura Española Contemporánea, núm. 32, pp. 205-226.

Santana, Mario, 2000, Foreigners in the Homeland: The Spanish American New Novel in Spain, 1962-1974, Bucknell University Press, Lewisburg.

Tola de Habich, Fernando y Patricia Grieve, 1971, Los españoles y el "boom”, Tiempo Nuevo, Caracas. 
Vargas Llosa, Mario, 1992, "Sombras de amigos", en El Pais, 7 de mayo, 1992, p. 13.

, 1998, "El día que me instalé en Sarriá" en Arcadi Espada, Dietario de posguerra, Anagrama, Barcelona, pp. 169-192.

Viñas, David et al., 1981, Más allá del boom: literatura y mercado, Marcha, México. 